\title{
Working Towards Sustainable Development of Sugar Cane in the Agro Industrial Sector: Scenarios to Veracruz 2030
}

\author{
By María Tapia-Baranda* \\ Guillermo Gándara Fierro ${ }^{\dagger}$
}

The lack of coordination between the different levels of government on public policies for the agro industrial sector sugarcane in Veracruz Mexico has serious consequences on social, economic and environmental areas. The objective of this research is to analyze the current situation, to reveal the key elements, and to propose strategies that activate the development of the sector with an approach for change in the future; involving a systemic understanding of present reality, to implement the changes required to reach the desired future. A SWOT analysis applied to the study exposes the actual conditions in the environments; where the strategic elements obtained were placed within a structural system for the sustainability of the sector, and where they were used to propose strategic planning. It was concluded that the variables to work and the derivative strategic issues are three: Infrastructure; Public Policy Development; and Research, development and innovation, by inspiring the creation of the necessary proposals.

Keywords: Strategic Elements, Strategic Planning, Structural Analysis, Sugar Sector, Sustainability.

\section{Introduction}

Mexico is one of the top 10 sugar producers in the world. Sugarcane is one of the most widely grown field crop, with cultivation in 15 of Mexico's 23 states. It is important to note that sugar is the primary agricultural industry in Mexico, directly and indirectly employing more than one million people. The cane field and production units are very small compared to the United States. Only a small percentage is larger than 10 hectares. The growers are well organized, with the land owners, the communal growers, the workers and the salaried employees, are represented by unions. The produced sugar is consumed by the domestic food industry, with the highest demand coming from the soft-drink industry. There is instability on domestic prices fueled by speculation and supply shortages (Buzzanell 2010).

High fructose corn syrup is an increasing part of the total Mexican sweetener use. Mexico imports HFCS directly from the US, as well as producing it domestically (largely from imported yellow corn). Since trade has been fully liberalized under NAFTA, corn can be imported at any time. Mexican farmers overwhelmingly plant white corn for human consumption and

\footnotetext{
${ }^{*}$ PhD Candidate, University of Valencia, Spain.

${ }^{\dagger}$ Technological Institute of Higher Studies in Monterey - ITESM, México.
} 
that is resistant to change due to lower yields of yellow corn compared to white and the difficulty in accessing quality seeds (Buzzanell 2010).

The need for coordination between different government entities and stakeholders, in order to create and implement policies that truly benefit the agribusiness sector of sugarcane in the central region of Veracruz, Mexico, has incalculable social, economic and environmental consequences.

There are many situations that do not allow stakeholders to find the agora to implement solutions to common problems that afflict them in order to consider working together. The different heads in government, from a municipal, regional or federal level, including ministries, have very little influence on the business processes and are not aligned with the objectives of the different projects.

This research was carried out with the prospective methodology of future developmental proposals over a 15 year period. This time frame was chosen to coincide with the previous stage of technological renovation for sowing and for factory processes, which agribusiness has been undergoing since 2000 .

The general objective is to diagnose the current situation regarding the sustainability of the sugar sector by revealing its key elements in order to recommend strategies that fully activate the development of the sugar industry within a sustainable approach by 2030 .

Among the specific objectives we will seek to identify the existence of the most important elements that promote sustainability in this sector; to quantify and evaluate the elements obtained in its influence and dependence for the performance in advancing or obstructing the full development of the sugar industry and to develop a proposal that promotes a desirable scenario for sustainable development in 2030. Thus, the changing roles of the stakeholders will have to ensure the sustainable and equitable use of natural resources, requiring an interdisciplinary approach from this prospective. A proposal based on knowledge as an opportunity for development and to accelerate the social and economic improvement can reduce poverty, conflict, livelihood vulnerability and risk of disease.

According to "La boîte à outils de prospective", the above aspects are reviewed and linked to the conditions and their determinant analogies to point out the way towards sustainable development in Veracruz. This starts with interviews with some specialists and with support from the bibliographic diagnosis to define the problem and to understand the context, simultaneously the "State of the Art" is molded with an octagonal structure of sustainability, and through the analysis of the external and internal features of the sector. Next, is the process of performing a structural analysis, this process is conducted using the Delphi method based on remote consulting to the different experts, finally a suitable strategic plan is put forward to make the wager scenario real.

The research is divided into five parts, the first part, refers to the theoretical concepts used throughout the proposal: Prospective, Public policies and Sustainability and presents a description of the methodology. Next, the paper describes the diagnostic stage with elements used in the octagonal model, 
SWOT and a structural analysis that interprets the given results. Subsequently, the findings and results from applying foresight methods are presented. In the last two sections, the paper describes the proposed strategy with the desired mission of promoting the implementation of appropriate key elements for development in terms of sustainability, and the conclusions of the process and some future lines of research.

\section{Theoretical Framework and Methodology}

\section{Conceptual Framework}

Based on the theoretical principles of foresight to articulate the needs of public policies for the sustainable development of the sector.

\section{Prospective}

Foresight is a new discipline that appeared in the last century where the dynamic, global, systemic, and open vision aimed to explain the possible futures, which must be: hypothetical, useful, relevant, understandable and integral. Strategic foresight is the tool that allows us, through consultation with the knowledge of expert's, to build a vision of what we want to achieve in the future, as well as to consider the obstacles that may stop us from achieving it. This also includes the measures that must be applied from the present to build a desired and possible future.

The general theory refers to the principles of strategic foresight where, according to the words of Eduardo Balbi: "Involvement and commitment can only be achieved under high-quality, executive, focused, realistic, and planned management and with a clear view of medium and long-term goals" (Balbi 2003).

\section{Public policy and politics}

Whatever school of planning is used, and regardless of the methodology utilized, all planning processes nowadays nail down public policies that have a close relationship with the political system and politics in general. They argue that public policies are a common mix of combining factors of politics, including government decisions and the opposition's ideas. Thus, politics management can be used as the search for establishing public policies, to block certain issues, or to influence them. On top of this, a key part of the work of the government refers to the design, management and evaluation of public policy. Politics and public policy are different entities, but reciprocally influence each other. Both the policy and public policy have to do with social power. But while the policy is a broad concept, relative to power in general, public policy corresponds to specific solutions on how to manage public affairs.

For public policy we understand the government's action to mobilize human, financial and institutional resources devoted to solving public problems in society. A public policy is formed by a set of sequential actions referred 
specifically to solve the causes of a public issue. Public policies can also include laws, programs and projects; they can allocate resources (public expenditure and taxes) or regulate activities (civil or criminal law) and are oriented to efficiency, because they seek to achieve the best results with the resources and facilities available (Aguilar-Villanueva 1996).

\section{Sustainability}

Neo-liberalism is a dominant economic condition in the world today that assumes that individuals can maximize their welfare and the welfare of their society if allowed to compete freely, buying and selling their goods in the market (Parthasarathi 2002). As a result of the current economic logic of the market, some ethical concerns are introduced: Is it enough pursuing individual interest? Is it free or is it being sheltered by specific political agendas and the benefit of corporate interests? Does this search really lead to the achievement of general interest? (Jiménez 2000).

Global competition often not only reflects a true increase in resource productivity, but also the competition to reduce wages, externalize environmental and social costs, and export natural capital at low prices while saying that the gross domestic product grows (Daly 2002). Already in 1862, John Ruskin (quoted by Daly) spoke of the GDP (Gross Domestic Product) of "what appears to be wealth, it can only truly be the happy index of the long term ruin".

The concept of sustainability was defined in 1987 by the Prime Minister of Norway Gro Harlem Brundtland, in the report submitted to the UN "Our Common Future" as: Meeting the needs of the present without compromising the resources for future generations (Brundtland 1987) (Figure 1).

Figure 1. Three-dimensional Model of Sustainability

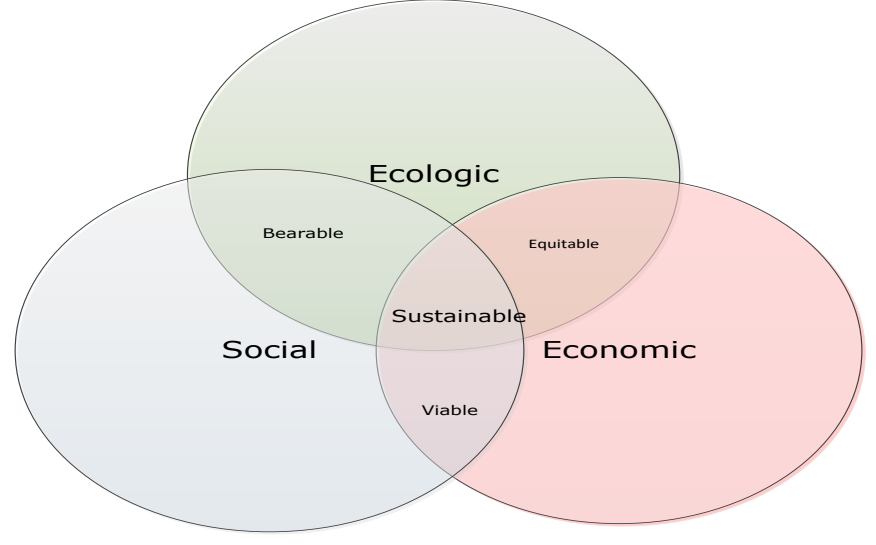

Jiménez (2000) notes that sustainability is not synonymous with sustainable development, this includes social objectives on a scale of the human needs and values established, and evolves over time and shapes it to an open process that is progressively enriched. When challenged to explain the development from the point of view of sustainability it is necessary to take into account the principle of intergenerational equity, which is the commitment to 
leaving a legacy for future generations by preserving capital without reducing, the living standards and welfare people enjoy today (Jiménez 2000).

The concept of sustainable development broadens the understanding of the impact of human activity on the planet and the interconnections between the social, economic and environmental systems. There are different models that incorporate other dimensions. Jimenez proposes his own model of four interrelated dimensions, described as systems: An ecological system for sustaining life on the planet and of human activity; an economic system that concentrates the production of material goods and services; a social system as a basis for the organization of society and institutions; and a fourth system of values, which involves the three previous systems and promotes a set of ideas and values for the man in their relationship with nature.

The method of analysis was adapted for the redefinition of new semantic categories, grouping words. A systemic model consists of six dimensions identified as: The first three categories that meet the nominal and concrete concept criteria, are often named as the three pillars of sustainable development. Category 1: cultural aspects; Category 2: environmental issues; and Category 3: economic, scientific and technical issues. The second aspect of sustainable development involves complex ideas: The multidisciplinary, the spatial disparity, and temporal relationships. Category 4: This category includes the principles of sustainable development; Category 5: Approaches the procedural law and policies; Category 6: Actors and stakeholders. Later, the authors Lozano-Garcia et al. (2008) on their book "Capacity building: a course on Sustainable development to educate the educators", decided to slightly modify the categories and expand the list to eight categories, so the economics of science and technology was separated and a category for education was incorporated. A conceptual map was used to locate elements in 8 areas or systems and to recognize the relationships they have between them (Figure 2).

Figure 2. Octagonal Model of Sustainable Development

\section{Enviromental}

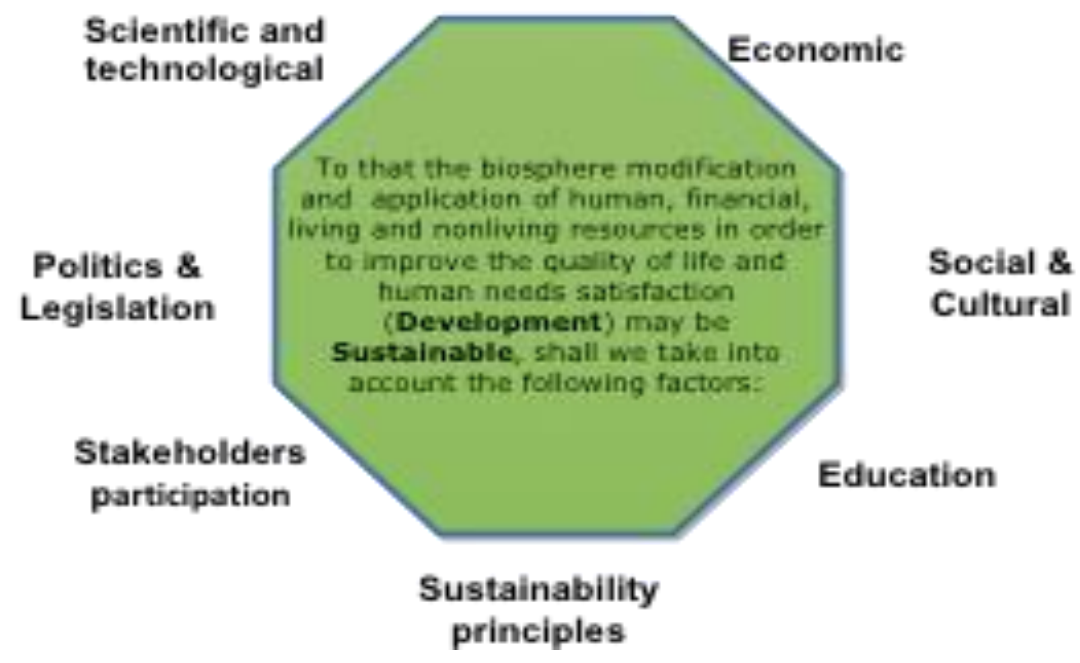


Thus, by approaching the theory with a vision of sustainability, the elements of study acquire a dimension of ethical value and become more human. The complexity vanishes by approaching the political theory and prospective disciplines with the idea of classifying the components of the structure in eight dimensions, an organization that is perceived at first appears as robust and easy to observe, despite the complexity of a topic such as sustainable development of the sugarcane sector.

\section{Methodological Framework}

The methodology is divided into four stages (Figure 3). In the first stage, individual investigation takes place to understand the context, based on primary and secondary sources; the following two steps focus on visualizing and drawing future scenarios to be performed with a group of experts using the Delphi method, questionnaires designed when SWOT was built, by defining the elements of structural analysis, to build the future and more probable scenarios. The final stage of building the future, relates to the most likely scenarios by selecting the best future scenario for which recommendations are made besides being a guide for strategic planning. It is important to distinguish between an exploratory phase that seeks to identify future challenges and a second strategic phase that investigates the definition of the possible and desirable options for the sugarcane sector and can help keep the path to these goals (Godet 2002).

\section{Firth stage - Understanding the context}

This work begins as shown in Figure 3, by conducting documentary research and the analysis of trends. To understand and to describe the state of the art, a conceptual map is built with an octagonal structure. In this stage the following were made: a field visit and some preliminary interviews with 6 experts involved in the area of sugar, sustainability and public policy, with the aim of knowing the context of the problem and that have a basis for the development of the Delphi questionnaires. 
Figure 3. Methodology of the Research

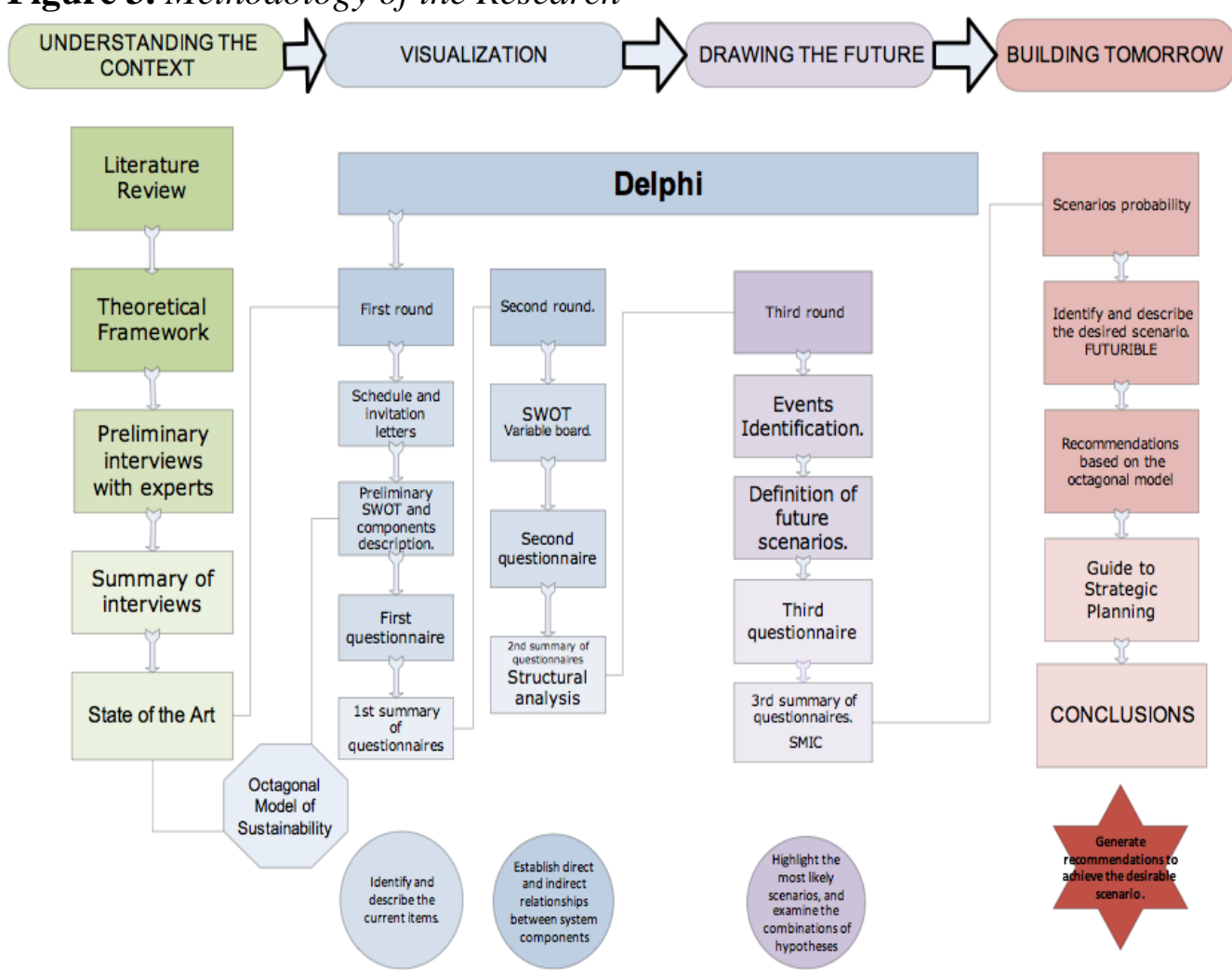

Second stage - Visualization

The Delphi method found the coincidences and reached the consensus through a series of questionnaires to the experts in the field. This method was chosen because it collects and summarizes information very efficiently. In addition it allows the articulation of the forward steps of the prospective process. With these techniques, qualitative methods will be used, because these procedures are based on the experience and intuition of experts and are directly and indirectly involved with the subject matter (Baena 2004).

It is divided into 3 phases for its application: problem formulation, selection of experts and exploitation of results. The method suggests that the richness of the results are based on the diversity of the disciplines of the experts chosen, as well as their depth of knowledge, for this reason people with experience in the production have been chosen, manufacturing and/or marketing of sugarcane; innovation; law and economy; development; knowledge and practice in the public service of the regional, local, or federal governmental level; and experienced specialists in the area of sustainability. The questionnaire was sent to a dozen experts, taking into account nonresponses and dropouts. The questionnaire was accompanied by a cover note that specified the purpose, the spirit of Delphi, and the practical conditions of the development survey (response time, anonymity guaranteed).

In the questionnaires, three elements are presented to the experts. The first element is an initial SWOT (strengths, weaknesses, opportunities and threats table), accompanied with an analysis sheet where what is meant by each 
statement is briefly described and serves to define the semantics and create a common language with all the participants. The second part of the questionnaire is a table of components that could become relevant in the system that is analyzed. Participants are asked to review, validate and add or remove them by considering their discretion and experience.

During the 2nd consultation, experts are informed of the results of the first questionnaire and should give a new answer (Godet 2002). With the contributions made by the experts, the final SWOT table is made with the precisions and suggestions collected. A variables' table is obtained as a basis to fill the second questionnaire consisting on the different phases of structural analysis: 1) list of variables, 2) the description of relationships between variables and the 3) identification of key variables performed using the software by LIPSOR called MICMAC* (Cross-Impact Matrices for Multiplication Applied for Classification). With the information gathered, the questionnaire is sent to establish the direct and indirect relationships between the system's components, to create the structural analysis, it provides the possibility to describe one, using a matrix by unfolding all its constituent elements. From this description, the method aims to bring up the main influential and dependent variables and therefore, those that are essential to the evolution of the system's variables (Godet 2002).

\section{Third stage - Drawing the future}

This space aims to highlight the most likely scenarios, examining combinations of hypotheses, and generates different strategies to achieve the most desirable possible future scenario. The protocol is based on paying attention to the most probable future events that will be collected by the scenario method in three phases: Phase 1: formulation of hypotheses; Phase 2: probabilization scenario, and Phase 3: the writing of scenarios.

\section{Fourth stage - Building the tomorrow}

This is the phase of work that describes a path that will move from the current to the future desired situation called "futurible scenario". The accurate representation of scenarios is useful to place the decision makers on the needs to find the right strategy and to achieve an agreement. It is also useful to describe the events that highlight the ruptures called "black swans", the strongest trends and the key events without fully specifying the entire path. Besides the description of the likely scenarios and the desired or "futurible" scenario, a guide for strategic planning is constructed according to the eight dimensions of the model, and the proposal of Dr. Daniel Meade Monteverde, a researcher in the area of management organizational change and strategic planning EGADE Bussiness School, ITESM.

Prospective studies should be contextualized in time and place to be useful, by the limitations of the calendar the final proposals and the strategic planning guide that was made by the researcher. 


\section{Diagnostic Stage}

Figure 4. Mind Map of State of Art by the Octagonal Model Sustainability Development

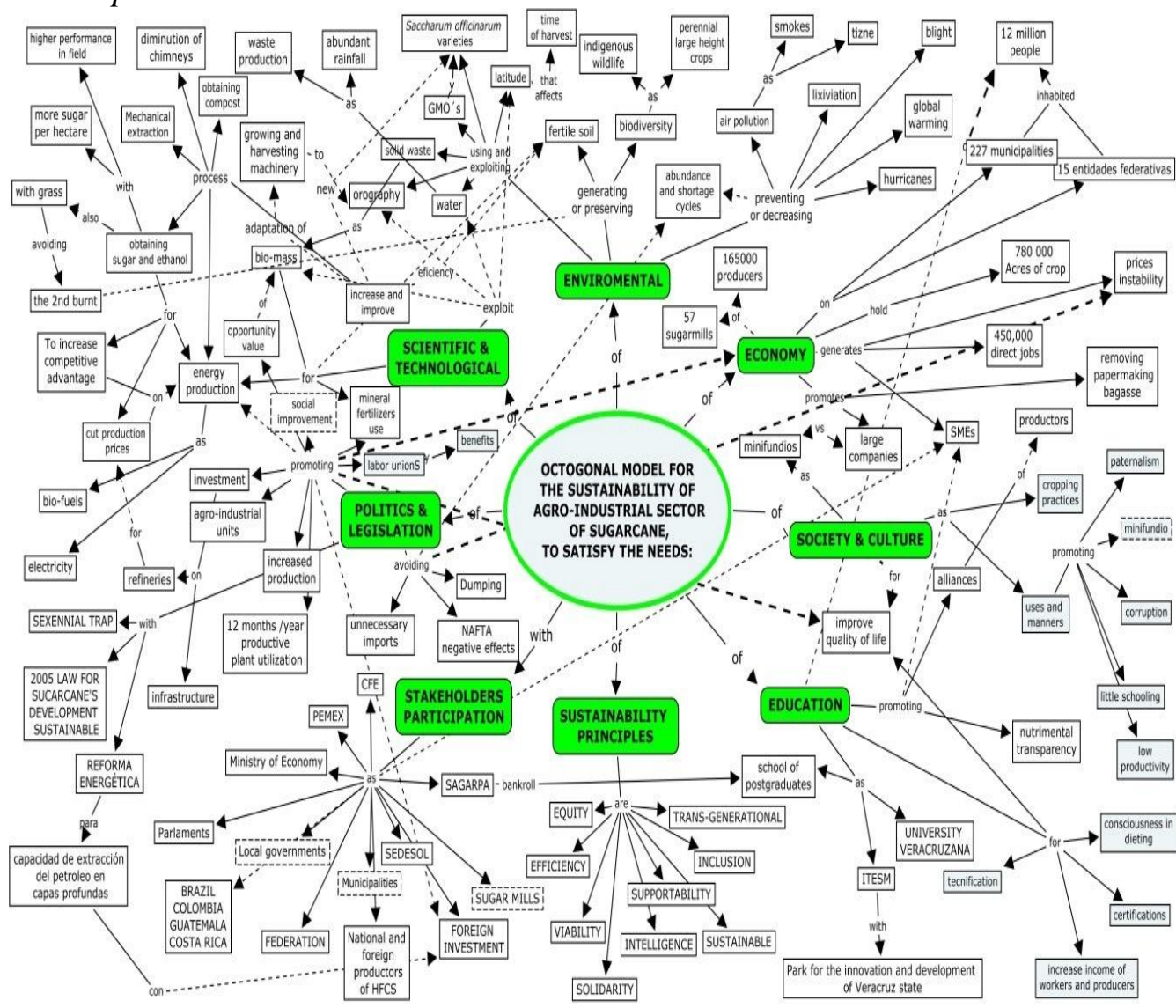

Source: Lozano-Garcia et al. (2008).

The SWOT Analysis

It was built with the Delphi first response, where ethical values of efficiency, practicality and intelligence are identified as strengths; equity, inclusion and supportability as weaknesses, and as opportunities to develop solidarity, sustainability and intelligence. By meeting all together the ethical values of sustainability to combat threats (Figure 5). 
Figure 5. SWOT Analysis of the Sugarcane Sector for their Sustainable Development (with Inputs Provided by Experts)

\section{SWOT analysis (with inputs provided by experts) for sustainable development of agroindustrial sugarcane sector.}

\begin{tabular}{|l|}
\multicolumn{1}{c|}{ STRENGTHS } \\
$\square$ Permanent increase on yields, \\
profitability and competitiveness \\
through modernization \\
$\square$ Potential for innovation \\
$\square$ Security and independence by \\
electricity generation \\
$\square$ Using bagasse for energy or raw \\
material. \\
$\square$ Versatility of sugarcane for different \\
products. \\
$\square$ Sugar mills infrastructure to diversify \\
production. \\
$\square$ Promotion of protection and \\
conservation of the environment by \\
some actors.
\end{tabular}

\begin{tabular}{|l}
\multicolumn{1}{c}{ OPPORTUNITIES } \\
$\square$ Improve knowledge transfer \\
processes \\
$\square$ Implementation of I+D+I in each step \\
of the production chain \\
$\square$ Advantage with the North American \\
markets \\
$\square$ Attracting foreign Investment \\
$\square$ Forming clusters \\
$\square$ Promotion of production units with a \\
sustainable base \\
$\square$ Detonate agglomeration economies. \\
$\square$ Policies for generation of capabilities \\
$\square$ Pollutants effects of MTBE \\
$\square$ Implementation of the energy reform \\
$\square$ Promotion of trans-generational and \\
ecological awareness \\
$\square$ New products for new markets \\
$\square$ Optimized water use \\
$\square$ Diversification on the industry \\
$\square$ Partnerships and linkages with other \\
sectors \\
$\square$ Modernization
\end{tabular}

EAKNESSESS

$\square$ High production costs

$\checkmark$ Law DSCA (2005)

Conflict of Interest

$\checkmark$ Sector highly politicized

Difficulties to financial access

$\square$ Need for investment

$\square$ Low I+D+I

$\checkmark$ Resistance to technological change

$\square$ Need for SME promotion programs

$\square$ Insufficient and poor Infrastructure

$\square$ Deficient education.

$\square$ Competitive advantages of substitutes (HFCS, MTBE)

$\square$ Inefficient sugar mills

$\square$ Need to adapt the equipment to the topography

$\square$ Highly polluting industry

$\square$ Vulnerability of people that harvested

$\checkmark$ Dependence on exporting to USA.

$\checkmark$ Dependence on imported inputs and equipment

$\square$ Need to link with other industries

\section{Syndicalism}

$\checkmark$ Competitive advantage of Latin-Americans countries (Brazil)

$\square$ Lack of adequate regulations

$\square$ Backwardness in the regulations to encourage the development and favorable conditions of international competition: subsidies, import quotas, dumping, substitutes.

$\square$ Floods and droughts

$\square$ Divergence (local and international) political interests

$\checkmark$ Changes on national policies on social, labor, tax,

energy. (Six-year trap)

Comparative advantage of MTBE

Competition from substitutes.

$\square$ Narcotraffic and criminal gangs

Lack of rule of law

$\square$ Taxes on soft drinks 
The list of variables for the SA shown in Table 1, is constructed using the results of the Delphi method with contributions of experts using 13 specific variables obtained, an acronym assigned to identify them when working in MICMAC software program; also a category of affinity, within one of the dimensions of sustainability in the octagonal pattern, is given.

Table 1. Strategic Variables - List for Structural Analysis

\begin{tabular}{|c|c|c|c|}
\hline & Variable & Acronym & Dimension \\
\hline 1 & Production Costs & Costo & Economic \\
\hline 2 & $\begin{array}{l}\text { Legislation and Indirect Regulatory } \\
\text { Instruments }\end{array}$ & Normat & Politics and Legislation \\
\hline 3 & Development Policies & PoPub & $\begin{array}{l}\text { Politics and } \\
\text { Legislation/Actors } \\
\text { Participation }\end{array}$ \\
\hline 4 & Competence & Compet & Economic \\
\hline 5 & Education & Educ & Education \\
\hline 6 & $\begin{array}{l}\text { Availability and Use of } \\
\text { Water/Environmental Protection }\end{array}$ & AguaMA & Environmental \\
\hline 7 & Social Capital & C Soci & Society and Culture \\
\hline 8 & Idiosyncrasy and Political Culture & Idiosin & Society and Culture \\
\hline 9 & $\begin{array}{l}\text { Research, Development and } \\
\text { Innovation }\end{array}$ & $\mathrm{I}+\mathrm{D}+\mathrm{I}$ & $\begin{array}{l}\text { Science and Technology/ } \\
\text { Actors Participation }\end{array}$ \\
\hline 10 & Infrastructure & Infra & $\begin{array}{c}\text { Economics/Environmental } \\
\text { Ambience }\end{array}$ \\
\hline 11 & Rule of Law and Safety in Cane Zones & EdoDere & Politics and Legislation \\
\hline 12 & $\begin{array}{l}\text { Diversification and Product } \\
\text { Accomplishment }\end{array}$ & Diversif & All \\
\hline 13 & Strategic Alliances & Al.Est & $\begin{array}{c}\text { Actors } \\
\text { Participation/Politics and } \\
\text { Legislation/Economics }\end{array}$ \\
\hline
\end{tabular}

Identify key variables with MICMAC

From the results obtained from experts, the average numerical rating is obtained and the software feeds: Crusaders Impact Matrices and Multiplication Applied for Classification by Lipsor, so we get a matrix plane (Figures 6 and 7 ), where the horizontal axis corresponds to the dependency and the vertical axis to the influence, making it easy to recognize the position of each one of the selected variables in their relationship with the others. 
Figure 6. MID (Matrix of Direct Influences)

\begin{tabular}{|c|c|c|c|c|c|c|c|c|c|c|c|c|c|}
\hline & $\begin{array}{c}\text { 1: } \\
\text { Costo }\end{array}$ & $\begin{array}{c}2: \\
\text { Norma }\end{array}$ & $\begin{array}{c}\text { 3: } \\
\text { PoPub }\end{array}$ & $\begin{array}{c}\text { 4: } \\
\text { Compet }\end{array}$ & $\begin{array}{c}\text { 5: } \\
\text { Educ }\end{array}$ & $\begin{array}{c}\text { 6: } \\
\text { AguaMA }\end{array}$ & $\begin{array}{c}7: \\
\text { C Soci }\end{array}$ & $\begin{array}{c}\text { 8: } \\
\text { Idiosin }\end{array}$ & $\begin{array}{c}9: \\
I+D+I\end{array}$ & $\begin{array}{l}\text { 10: } \\
\text { Infra }\end{array}$ & $\begin{array}{c}\text { 11: } \\
\text { EdoDere }\end{array}$ & $\begin{array}{c}12: \\
\text { Diversif }\end{array}$ & $\begin{array}{c}\text { 13: } \\
\text { Al.Est }\end{array}$ \\
\hline 1: Costo & 0 & 1 & 2 & 3 & 2 & 3 & 2 & 2 & 3 & 3 & 2 & 3 & 2 \\
\hline 2: Norma & 2 & 0 & 3 & 2 & 2 & 2 & 2 & 2 & 2 & 2 & 2 & 2 & 2 \\
\hline 3: PoPub & 2 & 3 & 0 & 2 & 3 & 2 & 2 & 3 & 2 & 2 & 2 & 2 & 2 \\
\hline 4: Compet & 3 & 2 & 2 & 0 & 1 & 2 & 1 & 1 & 3 & 2 & 1 & 2 & 2 \\
\hline 5: Educ & 2 & 2 & 2 & 2 & 0 & 3 & 3 & 3 & 2 & 1 & 2 & 1 & 1 \\
\hline 6: AguaMA & 2 & 2 & 2 & 2 & 3 & 0 & 3 & 2 & 2 & 3 & 2 & 1 & 1 \\
\hline 7: C Soci & 1 & 2 & 2 & 2 & 2 & 2 & 0 & 3 & 2 & 1 & 2 & 1 & 1 \\
\hline 8: Idiosin & 2 & 2 & 3 & 3 & 3 & 2 & 3 & 0 & 2 & 2 & 2 & 1 & 1 \\
\hline 9: I+D+I & 3 & 2 & 3 & 3 & 3 & 3 & 2 & 2 & 0 & 2 & 2 & 2 & 3 \\
\hline 10: Infra & 3 & 2 & 2 & 3 & 2 & 3 & 2 & 1 & 2 & 0 & 1 & 2 & 3 \\
\hline 11: EdoDere & 3 & 3 & 2 & 2 & 2 & 2 & 2 & 2 & 2 & 2 & 0 & 2 & 3 \\
\hline 12: Diversif & 3 & 2 & 2 & 3 & 2 & 2 & 1 & 1 & 3 & 3 & 1 & 0 & 3 \\
\hline 13: Al.Est & 2 & 2 & 2 & 3 & 2 & 2 & 2 & 2 & 3 & 3 & 3 & 3 & 0 \\
\hline
\end{tabular}

Note: The influences are scored from 0 to 3 , with the ability to identify possible influences: $0=$ No influence, $1=$ Weak, $2=$ Medium, $3=$ Strong, $\mathrm{P}=$ Potential. 
Figure 7. Influences/Dependencies Indirect Potential Plane

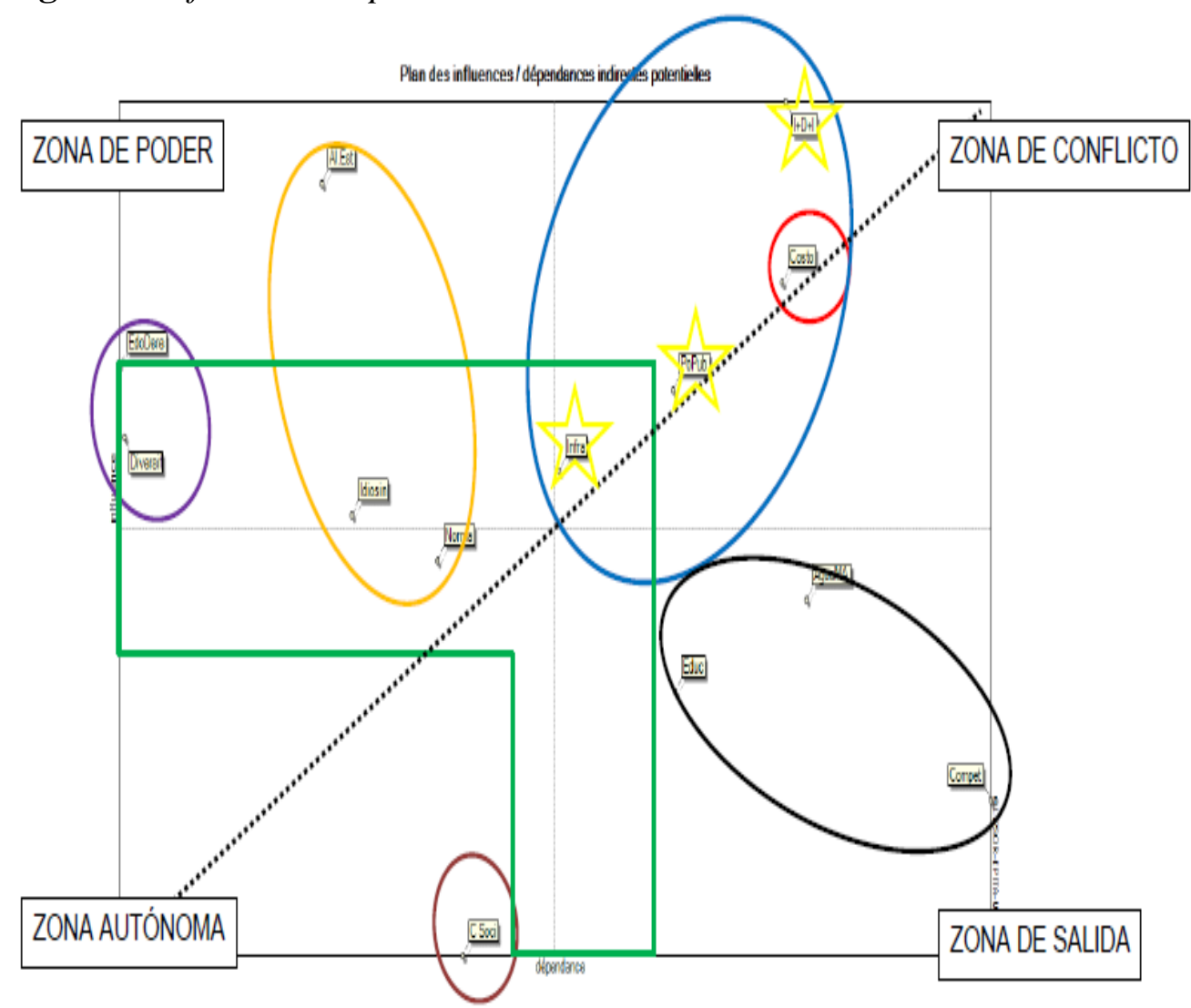

Note 1: ---: Variable target, ---: Key variables, -- : Regulatory variables, ---: Environment variables, ---: Variable autonomous, ---: Outcome variables, ---: Variables platoon.

Note 2: Variable target: The production costs. Key variables: Easy to modify and with relevant influence; Policies for development, Infrastructure and I+D+I. Regulatory variables: Normative, Idiosyncrasy and Strategic Alliances, this one has a strong influence and is considered important in building future scenarios. Environment variables: Diversification, Rule of law. Variable autonomous: Social capital. Outcome variables: Education, Competitors and Water use and environment protection. Variables Platoon: Those in a plane of medium influence and medium dependence.

\section{Building Tomorrow}

"Although prospective and strategy are closely related, they are different and therefore you should know how to differentiate them". The prospective, drives possible and desirable changes and prepares us for action; the strategy, appraises up and makes decisions to allow the expected changes (pre-activity) and cause desirable changes (pro-activity). This difference between exploring the situation and preparing for action, leads us to formulate five essential questions for a sector, region or organization to think about its future: Who am I? (Q1), What can happen? (Q2) What can I do? (Q3), What will I do? (Q4) and, How do I do it? (Q5) (Godet and Durance 2011).

Question one: Who am I? Involves going back to the origins, the following questions about the key skills, the strengths and weaknesses. Is the 
previous query about the identity of the company (or sector) which is often omitted? Is it the platform where the strategy originates? (Giget 1998, as cited by Godet and Durance 2011).

To plan future construction, founded on the SWOT analysis and the state of art with the octagonal model (Lozano-Garcia et al. 2008) where elements cannot be taken separately. After revealing the key elements and probabilistically evaluating those assumptions or future events (responses to question two) a set of recommendations is proposed to achieve goals and future optimum decisions (response to question three) following a structured plan and regular review actions (strategies) to sustainably activate the sugarcane sector plan (response to question four).

Recommendations, following the octagonal model of sustainability to pursuit to make the "futurible" scenario for 2030, were proposed as a guide to the strategic planning. To fully explain the relationship between strategy and foresight, the term "strategic foresight" refers to the foresight exercises with ambitious strategic goals for the actor that undertakes (Godet and Durance 2011) (response to question five).

Central Veracruz's inhabitants are recognized by their diligent and visionary spirit, they are responsible for managing and minimizing the risks, by achieving to optimize their question with a strategic approach. In this situation it decided to design a map of the Strategic Plan (Figure 8).

\section{Conclusions}

The objectives of this research and the future lines of research that this work could follow are presented in this paper. It offers a diagnosis of the current situation that is not conducive to the sustainability of the sugarcane sector, in as much as it treats the different areas of concern as isolated subjects. Three key elements are revealed: Infrastructure; Development policies; and Research, development and innovation.

Comprehensive recommendations for enabling the development of the sugar industry were made with a sustainable approach to 2030 and a map for strategic planning was built. With regard to the findings of other policies for the sector aligned with the goals of sustainability, a lack of public policies created specifically for the sugarcane sector was also uncovered.

In constructing the concept map to represent the state of the art with the octagonal model of sustainability, a visualization of the complex problems of the sector and their relationships can be observed, placing items in eight dimensions and how they are interrelated. Applying this octagonal model as a tool to determine the state of the art, achieved the goals of other tools designed for this purpose, but it is also a "checklist" to not leave out any of the three dimensions and to approach them with the integrity offered by ethical values, providing a different intention. By utilizing the same octagonal profile, and using the values to describe the various internal and external conditions in the SWOT, this acquires intentionality and reduces the complexity of observing the variety of elements. 
Figure 8. Diagram of the Strategic Plan of the Agro-Industrial Sector Sugarcane, according to the Model of Daniel Meade

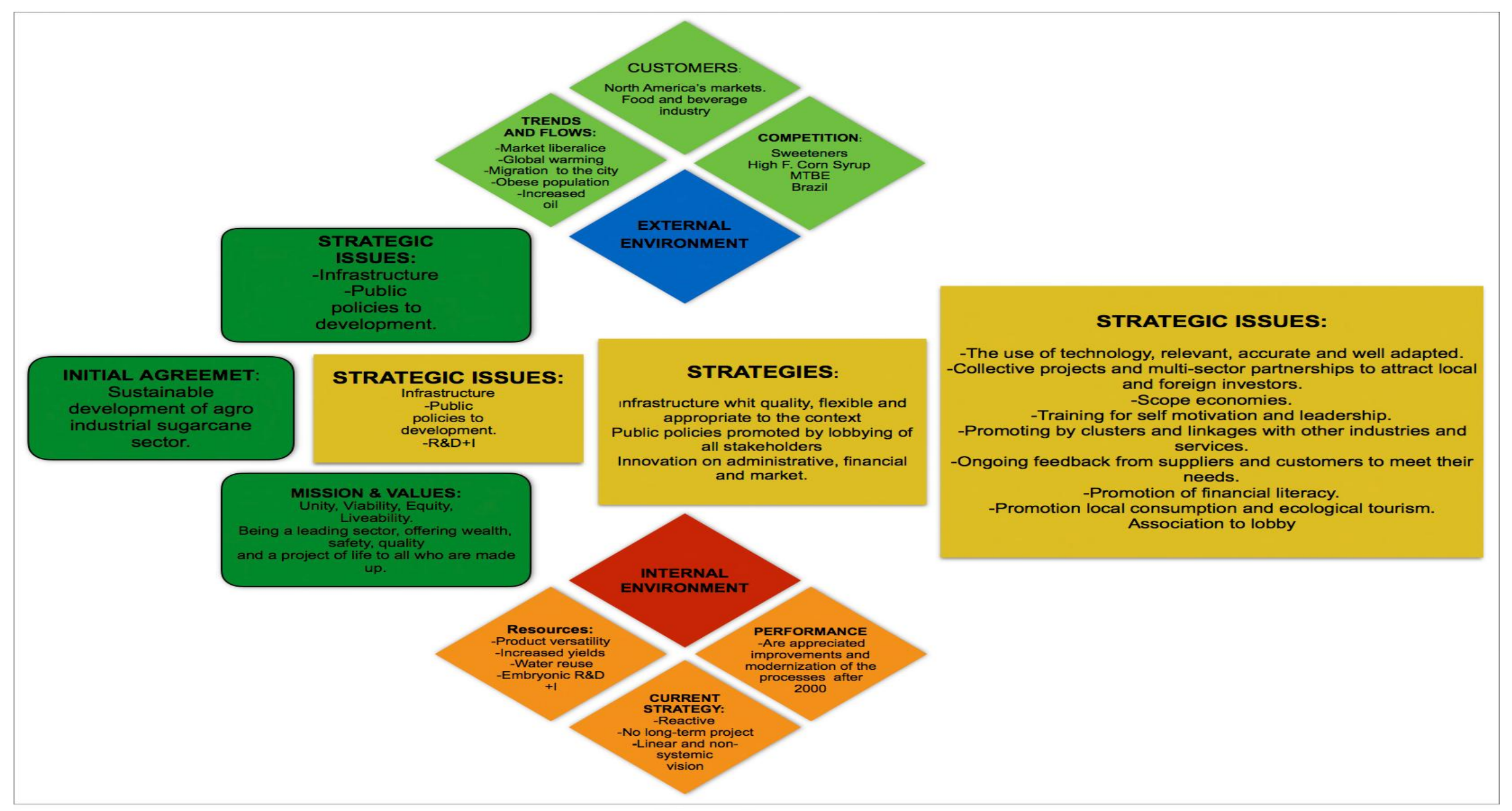


The results of the structural analysis graphically categorized and exposed the complexity of the systems under investigation, which facilitates their understanding avoiding prejudices or ideas without sustenance. But, as with the SMIC, to gather information from experts shows the appreciation of the diversity of approaches that sometimes come to be at odds, despite the difficulty by experts to assess and recognize the location of some elements seen within the system; ultimately they emerge and have a place within it. Direct and cross probabilities hypothesis and the resulting scenarios from SMIC gave lower than expected, which could partly be due to the same plurality of inputs.

A strategic map was constructed to graphically display and facilitate the understanding of how it goes from the ideas of the agreements, values or commands unto the execution of arranged actions.

To speak of the future lines of work and how it could continue, it is important to identify the relevance of the actors, so that they should apply a stakeholder analysis of the toolbox of foresight: the Mactor, once identified who the most relevant actors are, the diagnostic phase would be complete and would continue with the formation of a joint coordinating body for lobbying related to the sugar industry, so it has to make a design of a logical framework or roadmap for medium and long term action programs. Success depends on appropriation; internal motivation and external strategy, therefore, two inseparable objectives cannot be achieved separately. Competitive long-term growth depends on innovation and risk taking (Godet and Durance 2011).

\section{References}

Aguilar-Villanueva L (1996) El Estudio De Las Politicas Públicas [The study of public policy]. Mexico: Porrúa.

Baena G (2004) Prospectiva Política, Guía Para Su Comprensión Y Práctica [Prospective policy guidance for their understanding and practice]. Mexico DF: UMAN.

Balbi E (2003) Por Qué Investigar El Futuro? Prospectiva. Construyendo Futuros [Why investigate the future? Prospective. building future]. Buenos Aires.

Brundtland C (1987) 42/187 Report of the World Commission on Environment and Development. UN $96^{\text {th }}$ Plenary Meeting.

Buzzanell P (2010) Sugar In Mexico - An Industry Overview. Gilmore Sugar Manual. Retrieved from http://goo.gl/33XlKP.

Daly H (2002) Five policy recommendations for a sustainable economy. FEASTA Review 1. Retrieved from http://goo.gl/Gwbc8O.

Godet M (2002) La Caja De Herramientas De La Prospectiva [The toolbox of prospective]. Paris: Librairie des Arts et Métiers.

Godet M, Durance P (2011) La Prospectiva Estratégica Para Las Empresas Y Los Territorios [Strategic foresight for companies and territories]. DUNODUNESCO.

Jiménez LM (2000) Dinámica y multidimensionalidad de la sostenibilidad [Dynamics and multidimensionality of sustainability]. In LM Jiménez (edn.), Desarrollo 
Sostenible, transición hacia la co-evolución global [Sustainable development, global transition to coevolution] (pp. 99-119). Pirámide.

Lozano-García F, Gándara G, Perni O, Manzano M, Hernández DE, Huisingh D (2008) Capacity building: a course on Sustainable development to educate the educators. International Journal of Sustainability 9(3): 257-281.

Parthasarathi P (2002) Toward property as share: Ownership, community and the environment. In JB Schor, B Taylor (edn.), Sustainable Planet (p. 143). Boston: Bacon Press Boston. 
